Rev. Latinoam. Psicopat. Fund., São Paulo, 18(2), 397-399, jun. 2015

http://dx.doi.org/10.1590/1415-4714.2015v18n2p397.16

Encontro transcultural: subjetividade e psicopatologia no mundo globalizado Suzana Souza Pastori e Roseane Freitas Nicolau (Orgs.) São Paulo: Escuta, 2012, 212 págs.

\title{
Pathos, transculturalidade e globalização
}

Ronildo Deividy Costa da Silva*1

Resultado do Encontro Internacional de Psicopatologia Transcultural ocorrido na Universidade Federal do Pará em abril de 2010, este livro, coletânea de artigos organizada por Suzana Souza Pastori e Roseane Freitas Nicolau, professoras da Faculdade e do Programa de Pós-Graduação em Psicologia, tem como objetivo refletir sobre as consequências culturais e psíquicas do processo de globalização.

O trabalho de Cristina Lindenmeyer, fundamentado em sua prática psicanalítica com um menino brasileiro, faz trabalhar a hipótese de que as experiências de desenraizamento cultural podem provocar no sujeito intensa dificuldade em lidar com as perdas decorrentes dessa ruptura. Suzana Souza Pastori, ao tomar como ponto de partida a articulação entre autonomia e escravidão, contida

${ }^{* 1}$ Doutorando da Universidade Federal do Pará - UFPA (Belém, PA, Br). 
na origem do sentimento de brasilidade, usa o conceito de alteridade para refletir sobre a constituição subjetiva do brasileiro em termos psíquicos, culturais e sociais. O texto de Paulo Roberto Ceccarelli propõe, a partir da articulação dos conceitos freudianos de recalque (Verdrängung) e repressão (Unterdrückung), uma interessante reflexão sobre a incidência da perversão nas sociedades ocidentais e não ocidentais. Partindo da história da "cabeça voadora", presente em vários povos da América Latina, Betty Mindlin nos apresenta um belíssimo relato de sua experiência "onírica". Zélia Amador de Deus, tendo como referência as reflexões do psiquiatra e político Frantz Fanon, debate as dores do racismo no colonialismo e ressalta que o ideal de branquidade, da sociedade racista de hegemonia branca, é o fundamento da negação da alteridade.

Analisando a relação entre subjetividade e alteridade no processo de globalização, Maurício de Souza Rodrigues debate, a partir das ciências humanas e do referencial psicanalítico, a produção de subjetividades unidimensionais e a impossibilidade de lidar com as diferenças. Partindo, sobretudo, de Freud e Lacan, o texto de Roseane Freitas Nicolau analisa o sintoma globalizado do sujeito "contemporâneo" e ressalta, entre outras coisas, que em uma era de homogeneização dos sintomas é absolutamente necessário a afirmação da singularidade do desejo do sujeito como marca indelével do Inconsciente. Ana Rosa Chait Trachtenberg, partindo da diferença entre a transmissão psíquica transgeracional e intergeracional, aborda a questão do negativo e do indizível nas heranças familiares e nos lutos não elaborados. Partindo da psicanálise e do político, Caterina Koltai analisa o processo de construção das identidades na atualidade e destaca que, em tempos de violências etnocêntricas, o diferente torna-se ameaçador. Por fim, Zorca Domic, ao falar de seu trabalho com refugiados da antiga União Soviética e Iugoslávia, residentes em Paris, destaca a multiplicidade e as (des)construções identitárias dos sujeitos e sua relação com a estrangeiridade.

Acredito que, ao colocar em questão a dimensão cultural da psicopatologia a partir da experiência de profissionais de diversas áreas do conhecimento com o objetivo de refletir sobre as consequências psíquicas e culturais do processo de globalização, este livro demonstra a importância de uma prática clínica que, sem perder de vista a singularidade, possa dialogar com a transculturalidade do sofrimento humano.

Citação/Citation: Silva, R.D.C. da (2015, junho). Pathos, transculturalidade e globalização. Resenha do livro Encontro transcultural: subjetividade e psicopatologia no mundo globalizado. Revista Latinoamericana de Psicopatologia Fundamental, 18(2), 397-399. 


\section{RESENHAS BIBLIOGRÁFICAS}

Editor do artigo/Editor: Profa. Dra. Sonia Leite

Recebido/Received: 21.10.2014/ 10.21.2014 Aceito/Accepted: 19.12.2014 / 12.19.2014

Copyright: (C) 2009 Associação Universitária de Pesquisa em Psicopatologia Fundamental/ University Association for Research in Fundamental Psychopathology. Este é um artigo de livre acesso, que permite uso irrestrito, distribuição e reprodução em qualquer meio, desde que o autor e a fonte sejam citados / This is an open-access article, which permits unrestricted use, distribution, and reproduction in any medium, provided the original authors and sources are credited.

\section{Ronildo Deividy Costa da Silva}

Psicólogo; Mestre em Psicologia; Doutorando do Programa de Pós-Graduação em Psicologia da Universidade Federal do Pará (Belém, PA, Br); Psicanalista em formação pelo Círculo Psicanalítico de Minas Gerais (Belo Horizonte, MG, Br); Pesquisador do Laboratório de Psicanálise e Psicopatologia Fundamental - LPPF/UFPA (Belém, PA, Br); Bolsista da Capes (Brasília, DF, Br).

Tv. Maurití, 106 - Marco

66095-400 Belém, PA, Br

e-mail: ronildosilva010@yahoo.com.br 